\title{
Scientific and methodological support of future educators by means of distance education
}

\author{
Inna Gruzdova, Tatyana Emelyanova, Alla Oshkina*
}

Togliatti state University, Togliatti, Russia

\begin{abstract}
Improvement of the educational process at the university and, in particular, training of future teachers for professional activity is one of the priorities among social and scientific problems. The specificity of modern education is rapid development of electronic learning environment which entails a change in the ways of interaction between all participants in the educational process. It is important for a future teacher to master experience of scientific and methodological support in the educational process through electronic resources in the absence of a direct contact with students and their parents even during the period of professional training for successful professional activity. The purpose of the article is the theoretical substantiation and development of the content, forms and methods of scientific and methodological electronic support for training of a future teacher in conditions of industrial practice. To achieve this goal, the research results of domestic and foreign scientists and teachers (Atanasyan, Bolbat, Davidson, Farros., etc.) reflecting the types and possibilities of electronic support of students are analyzed and systematized. They are software and electronic educational and methodological support, electronic assessment system. The problems and difficulties that arise among students in organizing remote forms of educational activities are concretized by means of a questionnaire based on the results of various types of industrial practices. They are primarily associated with difficulties in using modern digital technologies and electronic support resources, an insufficient level of digital competence. The conclusion that the need to implement scientific and methodological support of the educational process in digital educational environment actualizes the individual experience of using IT technologies and forms of e-learning and interaction by the future teacher is made. The formation of this experience is possible in conditions of a practice-oriented educational process, including performing the program of industrial practices.
\end{abstract}

\section{Introduction}

Development of the modern education system is reflected in transformation of approaches to the learning process, optimization of technologies for formation of future specialists' professional competencies. Success and relevance of the teacher is associated with development of new models of building the educational process due to its openness to

* Corresponding author: allaoshkina@yandex.ru 
innovative experience. Therefore, improving the training of future teachers to work in a modern school is an important social and scientific problem that requires constructive ideas for development of new models of educational activities in the university and their scientific and methodological support. One of the variants of such models is the a posteriori model of professional training at the university which is presented as a promising model for acquiring professional experience and individual style of future teachers' activity in the scientific report "Theoretical and methodological foundations for building posteriori models of educational activity in a university", highlighting the results of the author's team research (Rudenko, Gruzdova, Yemelyanova, \& Oshkina, 2020). The concept of "a posteriori model" is determined on the basis of scientific knowledge and modern experience in expanding the scope and content of "practical training". The fact that the educational process requires expanding and enriching the forms of support by the professional development of students becomes objective. The most critical problems of Internet technologies introduction, virtual environment, evaluation of potential digital didactics development, the use of electronic textbooks and benefits are being discussed. The specific character of the intensively developing electronic environment of school education affects transformation of interaction methods of all participants in the educational process. The nature of interaction between the teacher and students, as well as parents, is crucial for cooperation and learning efficiency. However, as life showed, immediate contact is not always possible, and the problems associated with the distance participants in the educational process most clearly manifest themselves in terms of COVID-19 dissemination. Remote learning technologies are widely used at all levels of obtaining education today. The educational process is carried out using Internet technologies and telecommunications equipment with the territorial separation of participants in the educational process. Synchronous and asynchronous means of communications are actively mastered by teachers and students (Farros, 2020). Electronic scientific and methodological support of practical training, taking into account the emergence of new contexts in professional activities of the teacher, will make it possible to form a teacher who will have necessary experience and competences which are in demand at school.

\section{Purpose and objectives of the study}

The purpose of the study is theoretical substantiation and development of the content, forms and methods of scientific and methodological electronic support for training of the prospective teacher in the context of externship. To achieve the purpose of the study, the tasks of the research are identified and formulated. They are 1) to study features of scientific and methodological electronic support for practical training of future teachers through remote technologies; 2) to determine readiness of future teachers for scientific and methodological electronic support through remote technologies; 3) to reveal the future teachers' logic and content of electronic scientific and methodological support in the process of professional practical training on the basis of a posteriori component implementation

\section{Literature review}

The problem of designing and functioning of informational educational environment was raised in research of Abrahamyan (2020), Zakharova (2019), Kuryleva (2011) and others. The issues of educational informatization and implementation of the distance learning system are considered in the works of Andreeva (1999), Pastukhova (2018).

The authors consider remote technologies in the context of organization students' independent work with the use of Internet possibilities to ensure the processes of on-line of interaction and active exchange of information between teachers and students. Nowadays the 
number of studies on this issue has increased. Different aspects of the problem are considered. They are analysis of educational technologies, students' relation to remote technologies peculiarities of perception from e-learning content (Martinez, 2020; Anderson, 2020; RiveraVargas \& James, 2020). Experience of using distance technologies in training of higher education specialists was considered in the process of organizing practice (Kozlov, 2015), at the stage of adaptation to the university (Tsanhanov, 2015), in organizing independent work (Nordman, 2015; Rodkin, 2015), in students' preparation to various forms of training (Wagner \& Sasin, 2015), in teaching individual disciplines (Bogdanova, 2016; Makarchuk, 2004), with inclusive education (Oleinikov, 2017).

The works in which the means of electronic support for professional training of prospective teachers are considered in the context of the topic of research is of the greatest interest. Maina and Nzuki (2015) revealed determinants to implement the electronic training management system in higher educational institutions. Atanasyan (2009) substantiated feasibility of introduction of various means of informatization into a holistic unified medium of the pedagogical university and revealed specific character of the informatization for its individual structures. Factors stimulating students to use an online training system based on technologies integration are disclosed in the study of Kim et al. (2021). The method of interdisciplinary electronic projects as a set of educational receptions and procedures organized in the university's electronic environment is suggested in research of Krasavina et al. (2017).

The algorithms for development and implementation of electronic educational and methodological complexes in the educational process of the university, taking into account the specifics of various disciplines are introduced in works of Ilyashenko, Vaganova, Smirnova et al. (2018), Bulaeva, Koldina et al. (2018). The variability of service-oriented frameworks use for e-assessment as an integral structural component of distance learning is analyzed in the study of Al-Smadi, Getl and Helic (2009). The features of distance learning perception and e-assessment by university students are disclosed in the studies of Al-Smadi, Getl and Helic (2009), Ismaili (2021), Al-Emran and Salloum (2017). Osipova (2017) developed pedagogical support of an electronic portfolio for education managers studying for a master's degree. Tarinova (2017) suggested the author's interpretation of the experimental and analytical teaching model in relation to the process of forming part-time students' pedagogical competence by means of distance forms.

The analysis of scientific research state in the field of practice-oriented educational process support in higher education allows us to identify the types of electronic support of students:

- software support: professional software systems adapted to specific training practices and containing the basic components of future professional activities;

- electronic educational and methodological support: a set of educational and methodological tools (electronic, multimedia textbooks and workshops) that activate individual educational activities of students in the independent development of the discipline helping to master basic professional skills, prepare for work in real conditions (Bolbat, Petukhova \& Andryushina, 2019);

- electronic assessment system: various versions of electronic portfolios (creative training portfolios cuPortfolios, etc.), expert assessment (software peerScholar, Peer Evaluation, Assessment and Review (PEAR), etc.) (Davidson \& Thibodeau, 2016; Joordens, Paré \& Peer, 2013).

The most popular tools for software support of the educational process in foreign educational systems are the following; Mettl Certificate is the platform for managing online exams, the content of which includes psychometric, technical and cognitive tests. LearnCube is software for virtual classes, the features of which are characterized by presence of an interactive whiteboard, the ability to draw, print a text, upload content, record classes for 
further viewing by students, etc. iSpring Suite is a resource for quick and easy development of electronic courses, the specific features of which are integration with Powerpoint ( ability to create or use existing interactive and animated presentations), creation of interactive flipbooks, quizzes for students, high-quality simulations of conversations with branching for training, interactive glossaries, catalogs, chronologies, links, etc.

The experience of teacher-training institutions in the distance format allows us to analyze and systematize the results of the organization of students educational activities, including both development of individual training courses by prospective teachers, and professional practice, to identify digital services and tools that are most in demand and effective in these specific conditions. Here are examples of scientific and methodological support of practical training of Tolyatti State University students. To study the legal framework of the educational process, the course "Organization of research activities in an educational institution" successfully uses such programs as "Consultant Plus", "Garant". The information content of these systems is reliable and trustworthy, since the regulations come directly from federal and regional authorities and management. Students use Microsoft Office applications (Word, Excel, Power Point, Internet Explorer, etc.) to plan educational, extracurricular and educational work, as well as development of lessons content in the study of the courses "Theory of learning", "Theory and technology of familiarization of the younger student with the surrounding world" through application programs, including text, table, and image editors, and gain experience in their professional activities. It allows us to solve both the basic task of regulating information flows, and current educational tasks, such as developing tools for conducting psychological and pedagogical diagnostics of schoolchildren, preparing speeches in offline and online format at reporting events on development of the covered courses, at the final conference on pedagogical practice.

The means of electronic educational and methodological support for the educational activities of prospective teachers include practical courses and lectures developed on the basis of the MOOC service, web conferences on the Openmeeting, ClickMeeting, Mconf-Web platforms, etc. University teachers use Zoom cloud platform for video conferencing and webinars; Yandex Teleconference and Google Hangouts, the systems for video conferencing and webinar with the ability to publish materials on Youtube for connection with students and their counseling. It is possible to use the services of organizing joint project work GlobalLab and GitHub, which include tools for collecting, analyzing and visualizing materials and make it possible to conduct research projects (both student and student) and extracurricular activities in the practice-oriented educational process, including the project activities of students, and during practical training.

The means of the electronic assessment system used in the world and domestic pedagogical practice and implemented in the practical training of prospective teachers include services for checking SEO indicators of the text Antiplagiat.ru, TurnItIn, Content-Watch, Advego, tool environments for creating electronic portfolios Maharu, cuPortfolios, peerScholar, etc. A special subgroup of this category includes audience response systemsSlido and PollEverwhere interactive communication tools, which are applications that can be integrated into a PowerPoint presentation or other presentation software and allow audience members to answer questions from their mobile devices. The Slido app allows you to export questions and format them into an easy-to-read infographics. The CLikAPAD audience response system gives students the opportunity to answer questions by pressing a button. Future teachers have the opportunity to master and apply such electronic assessment tools as the Online Test Pad, designed for tests development, surveys and logic games during the training period. The electronic system for evaluating the students' results in educational activities is a point - grade-rating system (GRS) that generates success indicators in the form of an electronic interactive document MS Excel or Google-tables, including an electronic 
record book of current academic performance, a list of rating indicators, as well as a final list of grades.

Thus, firstly, prospective teachers receive necessary support, educational and methodological materials that correspond to the studied sections of disciplines and forms of conducting classes (workshops on disciplines, independent work, the internships, etc.), and secondly, they master necessary experience in the future professional activity of software, methodological and scientific support of the educational process.

\section{Methodology}

The analysis and generalization of modern constructive experience in the field under study, students' questionnaires, self-analysis of pedagogical activity were used in the course of research.

The research was conducted in the period of 2019-2021. Empirical data were obtained on the basis of studying the students' practice materials in the direction of training "Psychological and pedagogical education" and also on the basis of questionnaires. The experiment involved $952 \mathrm{nd}$, 3rd and 4th years bachelor's degree students of bachelor's degree in the direction of training 44.03.02 "Psychological and pedagogical education". Data collection for the study was carried out using questionnaires, analysis of practice reports. The participating students were aware of the purpose of the questionnaire. The survey was voluntary. The questionnaires were developed by a team of article's authors and aimed at identifying student's readiness for scientific and methodological electronic support in the process of practical training through remote technologies. The assessment was carried out according to the criteria allocated in accordance with the professional teachers' competencies and the competencies of the corresponding training standard. The obtained materials were processed using the methods of mathematical statistics with a help of SPSS 21.0.

\section{Results and Discussion}

The survey based on the results of the organization of students' education in Tolyatti State University revealed readiness of students for scientific and methodological electronic support in the process of practical training through remote technologies, and justified its organization (Fig.1).

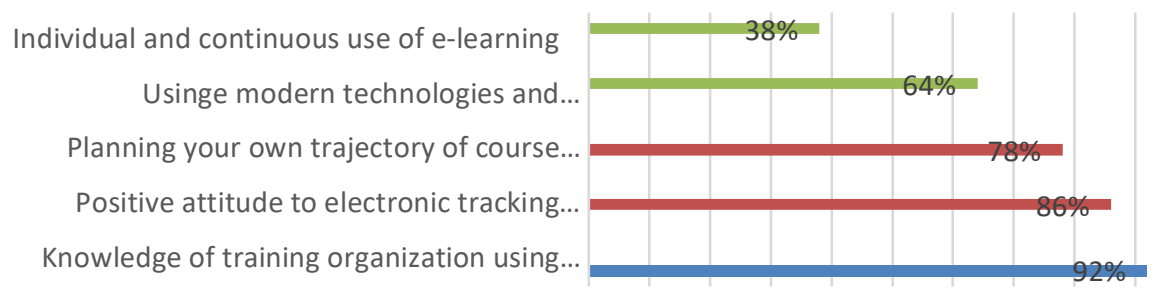

0\% $10 \%$ 20\% 30\% 40\% 50\% 60\% 70\% 80\% 90\%100\%

Fig. 1. Students' readiness for electronic scientific and methodological support through remote technologies.

The majority of students underlined necessity to implement electronic support and highlighted its positive aspects $(86 \%)$. In their opinion, the inclusion of electronic support into the educational process will help to overcome difficulties associated with planning their own trajectory of the course $(78 \%)$; the use of modern digital technologies and programs in 
the educational process during practice $(64 \%)$; the use of e-learning resources $(38 \%)$ in perception and understanding of pedagogical experience. $77 \%$ of respondents noted the potential of remote technologies in students' training. 34\% experienced difficulties in learning with the use of remote technologies at the first stage, $18 \%$-at the subsequent (after the adaptation stage).

Respondents noted that the use of remote technologies allowed organizing access to electronic resources. It provides an opportunity to discuss difficulties in solving professional problems or emerging issues at the forum during the survey. The students pointed out the importance of the course interface design, the volume of suggested materials for the course, the duration of video lectures and practice-oriented tasks.

The electronic educational environment allows a teacher to get feedback. A student places completed tasks for the training course and receives comments on its quality. Electronic support assumes that students at all stages of practice are involved in interaction with the teacher of the discipline. However, the analysis of this group of survey participants showed a low level of information competence.

It is proved that modern higher education is actively developing in the space of digitalization of educational environment. However, as the study showed, there is discrepancy between requirements of future teacher's professional training informational support and students' readiness to master the experience of professional activity in conditions of distance learning. The revealed level of modern students' low readiness for independent learning in digital educational environment allows us to raise questions about the need to develop scientific and methodological electronic support in education. In our opinion, the gradual introduction of electronic support for practical training in the process of distant learning forms implementation at the university allows to overcome the existing difficulties in experience of mastering the teaching profession.

When organizing interaction with a teacher, there is transition from direct communication to an increase in the share of indirect communication through electronic educational complexes and educational resources that are variable in content and form. This increases the volume of student's accumulation of independent professional experience in organization of cognitive and practical activities. The logic and content of electronic scientific and methodological support are built in accordance with the previously developed posteriori model of future teachers' professional training, which aims at formation of students' individual professional experience. (Rudenko \& Oshkina, 2020). The first stage of practical training is determined by students' direct immersion into a situation of a "problem nature" which maintains the students' need to acquire new knowledge and involves development of an author's electronic portfolio. The content of the portfolio is determined by tasks of a particular type of work practice and is filled in accordance with the individual interests and achievements of the future teacher. It contains materials of a methodological nature, suggesting generalization of advanced pedagogical experience in those issues of teaching and raising children that correspond to the program of work practice. The portfolio is placed in electronic educational environment of the university. The student interacts with the teacher using remote technologies at this stage. Exchange of knowledge about search sources, discussion of found materials, analysis of modern pedagogical experience, methodological support of the educational process take place.

The role of electronic support increases at the stage of analyzing your personal experience in solving upcoming production tasks. Students actively use remote technologies for working with electronic resources: electronic educational resources, electronic libraries, webinar materials, electronic textbooks. Our observation of students' actions at this stage recorded difficulties in choosing the right necessary and appropriate resource for solving problem situations. Therefore, constant contact and consultations are important. This interaction is implemented using remote technologies. 
During the practical training, the encountered difficulties were also overcome in the process of constant contact with the on-line teacher. Forums organized in the electronic content of courses and disciplines, placed in the electronic educational environment helped in it. Such interaction maintains individual experience, allows to decide on the choice of a self-learning strategy and contributes to formation of your own style of professional activity and universal competencies.

The stage of new knowledge internalization, and then its integration into experience of professional activity, required students to increase the share of independence in developing new ways of action that had not previously been encountered in the learning process and direct practice. Electronic support activated the students' independence in the process of making professional decisions. For example, the program of work practice (technological/production-technological) assumed that students would perform research tasks, the topics of which are initiated by an educational organization. Prior preparation is required for decision making. Students studied the content of educational organizations' websites, got acquainted with the directions of the educational organization's research activities and studied teachers' innovative experience. Based on the received information, students could make decisions about participating in research activities of the educational organization scientific problems of which are most interesting to the future teacher. The idea of taking into account the needs of practice and existing competencies in solving professional problems was taken as a basis for choosing the topic and problem of future research. This approach provided future teachers' interested attitude to scientific research and independent scientific creativity.

High-quality performance of working practice research part by students was also provided by electronic support of lectures on the studied theoretical disciplines. The electronic educational environment of the university includes the contents of courses, indexes of information resources on the subject of research works performed at the graduating department; electronic textbooks and methodological guidelines for implementation and design of research work posted on the website of a university scientific library; methodological recommendations for implementation of practical tasks in work practice, as well as examples of ready-made research works; control and diagnostic tasks designed in a specific program aimed at conducting research sections.

Electronic support resources are available to each student in their personal account. Documents and materials necessary for independent research work are freely available on the university's website, and are also posted on the websites of the electronic library, the educational and methodological department and on the website of the graduating department.

Prospective teachers actively used platforms with remote (group) courses in most subjects of the school curriculum during the practical training, ("Prosveschenie", "School digital platform", "Foxford", "Open School", library of video tutorials "InternetUrok.ru", "Yandex. school", etc.), collections of interactive tasks and simulators ("Uchi.ru", "Yaklass", etc.). It is also possible to use the services of organizing joint project work GlobalLab and GitHub, which include tools for collecting, analyzing and visualizing materials and making it possible to conduct research projects (both student and student) and extracurricular activities during the internship. Thus, prospective teachers simultaneously receive the necessary support during the internship and in the same time they master experience of implementing software and methodological support into the educational process.

Students' independent pedagogical and research work in the course of work practice requires a certain algorithm for accessing electronic support resources, as well as feedback. One of the forms of indirect interaction between the teacher and students during the practice is the developed educational web-quest "The Route of work practice". The web quest allows each of the participants to develop an individual route and navigate the most difficult tasks without losing time, finding up-to-date information for solving the tasks set. Thanks to the 
developed program of hyperlinks and creative tasks, students were aimed at using highquality Internet resources, focused on logic of conducting scientific research, ways of reconstructing professional experience and the system of a posteriori knowledge.

The implementation of a step-by-step algorithm for electronic support of students' practical work, as well as the individual trajectory of the practice program allowed us to develop a comfortable rhythm of activity, gave confidence in performance of tasks and the program of work practice. Working according to the algorithm of the web-quest, students independently mastered the ways of integrating theoretical, methodological and empirical information, learned to evaluate its advantages and disadvantages, apply experience gained in practice, carry out independent selection of materials and include the results of experience gained in practice in the system of professional knowledge.

The conducted research revealed a number of problems that require further solutions during implementation of distance learning technologies and electronic scientific and methodological support for the practical training of prospective teachers. Electronic support of the prospective student's practical training allows to fully implement the tasks of mastering the ethical side of the content of scientific and pedagogical activities. The emerging communication difficulties in solving practical problems related to the technology of implementing distance learning at the university require improving teachers and students' information culture, as well as expanding the range of competencies in the field of digital didactics.

The modules of professional training disciplines of the Bachelor of Pedagogy should be supplemented with practical competencies that allow mastering modern distance learning forms. It is necessary to describe competencies of the prospective teacher in the field of implementing distance technologies in school education, the ability to develop content for school subjects independently, observing the ethics of working in a digital environment. In this regard, the development of electronic support for prospective teachers' practical training needs to strengthen the technological block aimed at developing students ' professional responsibility for the quality of methodological materials being developed, the need to observe professional ethics in scientific and scientific-methodological creativity, development of the qualities of introspection and reflection in conditions of remote communication. A special area implementation of distance learning technologies deals with development of a prospective teacher's communication style at different levels of professional interaction. These issues limit the possibilities of the conducted research and require further resolution.

\section{Conclusion}

Remote learning technologies are actively getting used to the daily life of educational organizations. In this regard, improvement of professional training for future teachers is a necessary condition for modernization of the teacher education system. Time requires that the teacher is able to expand the boundaries of the established didactic models of teaching and the principles of organizing the training of schoolchildren. It is necessary to implement them into the pedagogical system at a qualitatively new level and apply modern remote learning technologies. The willingness to work successfully in changing conditions is ensured by synthesis of theoretical and a posteriori knowledge. Training with the use of remote technologies and electronic support of educational activities maintains the posteriori nature of knowledge and importance of practical experience in the content of professional training. The purpose of scientific and methodological support of practical training for prospective teachers in a broad sense was to create conditions for productive independent educational activities of students at the university, development of variable ways of accumulating professional experience. Electronic support of practical training of the prospective teacher 
expands the range of a posteriori knowledge in search for missing information, the use of modern technologies, in the organization of interaction between participants in the educational process in order to overcome difficulties, achieve planned results, and discover new ways to build pedagogical systems.

\section{Acknowledgments}

The reported study was funded by RFBR, project number № 20-013-00126 A.

\section{References}

1. M. Al-Emran, S. A. Salloum, Students' Attitudes Towards the Use of Mobile Technologies in e-Evaluation International, Journal of Interactive Mobile Technologies (iJIM), 11(5), 195-202 (2017)

2. M. AL-Smadi, Ch. Guetl, D. Helic, Towards a Standardized E-Assessment System: Motivations, Challenges and First Findings, International Journal of Emerging Technologies in Learning (iJET), 4, 2009. Access mode: https://doi.org/10.3991/ijet.v4s2.919

3. S. L. Atanasyan, S. G. Grigoriev, V. V. Grinshkun, Designing the structure of the information educational environment of a pedagogical university, Informatics and Education, 3, 90-96 (2009)

4. S. L. Atanasyan, Experimental practice of introducing an information educational environment in a pedagogical university. Bulletin of the Russian University of Friendship of Peoples. Series: Informatization of Education, 3, 16-21 (2009)

5. O. B. Bolbat, A. V. Petukhova, T. V. Andryushina, Electronic educational and methodological support of disciplines, Educational technologies and society, 2 (2) (2019). Access mode: https://readera.org/jelektronnoe-uchebno-metodicheskoe-soprovozhdeniedisciplin-140240303

6. M. N. Bulaeva, O. I. Vaganova, M. I. Koldina, A. V. Lapshova, A. V. Khizhnyi, Preparation of bachelors of professional training using MOODLE, Advances in Intelligent Systems and Computing, 622, 406-411 (2018)

7. A. Davidson, R. Thibodeau, Integrating ePortfolios at Carleton University in Ottawa, Canada, Contact Nord (2016). Access mode: https://teachonline.ca/pocketsinnovation/integrating-eportfolios-carleton-university-ottawa-canada

8. J. N. Farros, L. A. Shawler, K.S. Gatzunis, et al. The Effect of Synchronous Discussion Sessions in an Asynchronous Course, Journal of Behavioral Education, 6 (2020). Access mode: https://doi.org/10.1007/s10864-020-09421-2

9. S. Joordens, D. Peer Paré, Assessment and More with peer Scholar, Contact Nord (2013). Access mode: https://teachonline.ca/pockets-innovation/peer-assessment-and-morepeerscholar

10. L. K. Ilyashenko, O. I. Vaganova, Zh. V. Smirnova, M. L. Gruzdeva, A. V. Chanchina, Structure and content of the electronic school-methodical complex on the discipline "Mechanics of soils, foundations and foundations, International Journal of Mechanical Engineering and Technology (IJMET), 9 (4), 1088-1096 (2018)

11. Y. Ismaili, Evaluation of students' attitude toward distance learning during the pandemic (Covid-19): a case study of ELTE university (2021). Access mode: https://doi.org/10.1108/OTH-09-2020-0032 
12. E.-J. Kim, J. J. Kim, S.-H. Han, Understanding Student Acceptance of Online Learning Systems in Higher Education, Sustainability, 13 (2), 896 (2021). Access mode: https://doi.org/10.3390/su13020896

13. Yu. V. Krasavina, O. F. Shikhova, Method of electronic interdisciplinary projects as an effective form of organizing the independent work of university students, Education and science, 1, 160-176 (2017). Access mode: https://doi.org/10.17853/1994-5639-2017-1160-176

14. M. K. Maina, D. M. Nzuki, Adoption Determinants of E-learning Management System in Institutions of Higher Learning in Kenya: A Case of Selected Universities in Nairobi Metropolitan, International Journal of Business and Social Science, 6 (2), 233-248 (2015)

15. O. P. Osipova, Electronic portfolio in the education managers training system, Science and school, 2, 59-64 (2017)

16. I. V. Rudenko, A. A. Oshkina, Designing a posteriori model of professional training of future teachers at the university, Azimut of scientific research: pedagogy and psychology, 2 (31), 225-229 (2020)

17. I. V. Rudenko, I. V. Gruzdova, T. V. Emelyanova, N. A. Nefyodova, A. A. Oshkina, D. A. Pisarenko, Theoretical and methodological foundations of building posteriori models of educational activity of the university. Scientific report (2020)

18. N. V. Tarinova, Methodological grounds for the formation of pedagogical competence of correspondence students in the conditions of distance learning, The world of science. Pedagogy and psychology, 6 (2017). Access mode: https://mirnauki.com/PDF/21PDMN617.pdf 